\title{
Impact of Vendor CMMI Capability on User System Success Perception and Its Interaction With Trust in an IT Outsourcing Project
}

\author{
Sameer Dutta \\ McKendree University \\ Olu Omolayole \\ Grambling State University
}

\begin{abstract}
The study investigated relationship between Capability Maturity Model Integration (CMMI) capability of the vendor and user system success perception in IT outsourcing projects. Interaction between trust and CMMI-system success perception relationship was also investigated. Data was collected from IT professionals with background in both CMMI and IT outsourcing. Results reveal that while CMMI had no impact on a user's system success perception, trust did significantly interact with the relationship between vendor CMMI capability and user system success perception.
\end{abstract}

Keywords: IT outsourcing, trust, system success

\section{INTRODUCTION}

Offshore outsourcing of information systems has seen considerable growth over the recent past (Dibbern, Winkler, \& Heinzl, 2008). Global expenditures on IT outsourcing were projected to reach US\$161 billion by 2007 (Gartner Research, 2007). It had reached US\$ 288 billion by 2013 (Statista.com 2015). The theory of absolute advantage, first propounded by Adam Smith (1776), is considered to be one of the major explanations behind the phenomenon of outsourcing (Gefen \& Carmel, 2008). According to this theory, work tends to move to locations of lower cost. Thomas Freidman's (2005) "world is flat" thesis also points to the same effect (Gefen \& Carmel, 2008). IT outsourcing has been defined as the provision of services by a vendor to a client (Klepper, 1995), as the act of subcontracting (partial or whole), IT work to an external vendor (Altinkemer, Chaturvedi, \& Gulati, 1994), and management of a firm's IT infrastructure through governance mechanisms established with other firms (Loh \& Venkataraman, 1992). Thus, IT outsourcing means entrusting a vendor with part of the organization's IT projects or functions, such as software development and maintenance, network and computer operations, and research and development, for a specific duration (Dutta \& Roy, 2005).

From a technical perspective, outsourced software projects need to be executed with technical professionalism to ensure success. During the last decade, software process improvement (SPI) has emerged as the dominant approach to improving quality and productivity in software development organizations and has been highly influential in the evolution of better software-engineering practices around the world (Ngwenyama \& Nielsen, 2003). The prominent SPI methodology in use today is Capability Maturity Model Integration (CMMI). CMMI is the culmination of efforts by the Software Engineering Institute (SEI) to 
integrate preexisting capability-maturity models into a single model to eliminate inconsistencies and duplication and to streamline the SPI process (Huang \& Han, 2006, Royce, 2002). CMMI is a processimprovement approach that provides organizations with the key elements of effective processes. CMMI helps integrate traditionally different organization functions, set process-improvement goals and priorities, offers guidance for quality processes, and establishes a point of reference for appraising current processes (SEI, 2008).

In CMMI, process improvement is based on many small, evolutionary steps rather than revolutionary innovations. These evolutionary steps are divided into five maturity levels, each of which is a foundation for the next step in the process. Each level consists of a set of process goals that, when realized, establish the achievement of improvement to that level. These five levels are (a) initial, (b) repeatable, (c) defined, (d) managed, and (e) optimizing (Paulk, Curtis, Chrissis, \& Weber, 1993). At the initial level, the software process is defined as ad hoc and chaotic. A successful software development process is due more to individual effort than to any characteristics of the process itself. At the repeatable level, fundamental processes are put into place to track costs, schedules, and functionality. Based on previous experience, success is made achievable for similar projects. At the defined level, the software process for management and engineering activities is documented, standardized, and integrated into a standard software process for the organization. All projects use an approved, tailored template of the standard software process for the software development and maintenance activities. At the managed level, detailed quantitative measures of the software process and product quality are gathered. These quantitative measures are used to understand and control the software process and products. At the optimizing level, continuous improvement is enabled by quantitative feedback and by application of innovation to technology and ideas (Paulk et al., 1993).

The CMMI model classifies software development organizations into five hierarchical maturity levels: Level 1 is the lowest and Level 5 is the highest. An organization at Level 5 is considered a mature software development organization with highly effective software development processes in place ensuring predictability in results. In mature organizations, software development is carried out according to planned and well-defined processes in which roles and responsibilities are clear; schedules and budgets are realistic and based on historic data; cost expectations are met; and product quality is achieved (Ngwenyama \& Nielsen, 2003). An organization at Level 1 is considered to be immature employing ad hoc processes with generally unpredictable results (SEI 2008). Software development in immature organizations is accomplished by improvising as opposed to adhering to rules. Software functionality and quality are often compromised to meet deadlines. Schedules and budgets are not based on realistic estimates and are routinely exceeded.

FIGURE 1

\section{CMMI LEVELS}

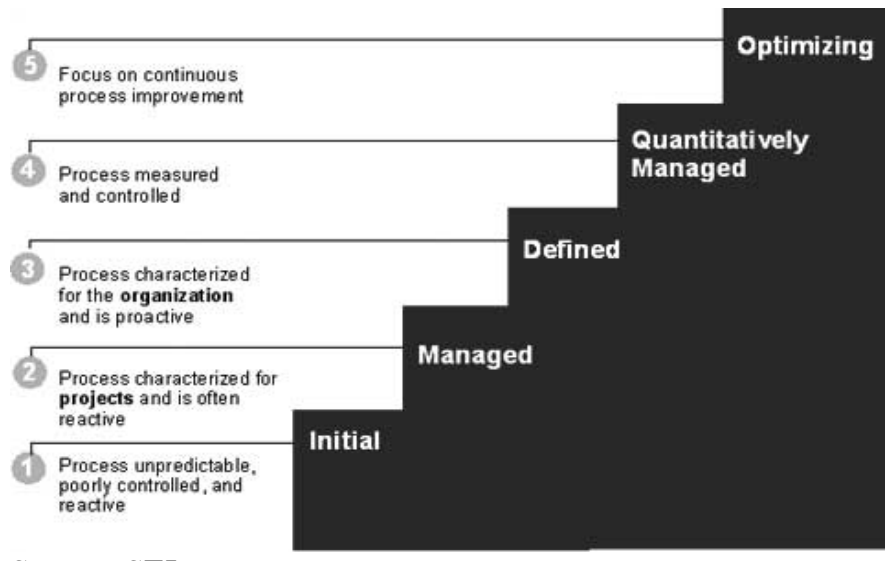

Source: SEI 


\section{ADVANTAGES OF CMMI ADOPTION}

The advantages of adopting CMMI have been reported by many researchers. Subramanian, Jiang, and Klein (2007) found that higher levels of CMMI or process maturity were associated with better software quality and project performance. Each CMMI level improves quality by a factor of 2, usually reduces cycle time, and also improves productivity (Diaz \& Sligo, 1997; Harter, Krishnan, \& Slaughter, 2000). Consistently adopting CMMI reduces defects in software products (Harter \& Slaughter, 2003; Krishnan \& Kellner, 1999). Tailored, firm-specific models of CMMI provide superior effort estimation of software projects (Maxwell, Wassenhove, \& Dutta, 1999), whereas Clark (2000) noted that one level of change in maturity reduced effort by 3 to $15 \%$. Process maturity plays an important role in determining product quality, development efforts, and cycle times (Harter et al., 2000; Parzinger \& Nath, 2000). The disciplined methods and practices described in CMMI process models can provide benefits to software firms, such as improved quality and reduced cycle time and cost (Herbsleb, Zubrow, Goldenson, Hayes, \& Paulk, 1997). CMMI has been highly influential in software engineering practices around the world (Ngwenyama \& Nielsen, 2003). Firms certified in CMMI have been found to have better management practices and higher operational performance (Isaac, Rajendran, \& Anantharaman, 2004).

A 2003 SEI report stated that although an increase in CMMI level did increase development effort, the associated improvements in quality reduced overall project duration through reduced rework and improved understanding of software requirements (Goldenson \& Gibson, 2003). At CMMI Level 5, the cycle time of software development is about 8 times faster than at Level 1 (Diaz \& Sligo, 1997). Reductions in the defect rate and cycle time reflect the capabilities that an organization achieves to deliver a software project in a consistent and predictable manner.

Therefore, high CMMI rating of the vendor provides greater assurance to the client that the vendor is equipped with the required technical capability required to complete the project. However, existent research has not fully investigated whether CMMI rating of the vendor can generate system success perception in the mind of the user. Accordingly, one of the hypotheses investigated by this study is that high CMMI rating of the vendor will be positively related to system success perceptions of the user.

\section{TRUST}

IT outsourcing projects have displayed less than stellar success in the past (McDougall, 2006). The primary adverse issues in IT outsourcing of projects are monetary, project, and technology related (Benaroch, Lichtenstein, \& Robinson, 2006; Gefen et al., 2008). Traditionally, parties to a project have tried to negotiate project issues using formal contracts. Although parties to an outsourcing project might take all due care in designing formal contracts, the bounded rationality of the actors imposes significant information gathering and processing costs in designing complete comprehensive contracts (Hart, 1995; Simon, 1957; Tirole, 2007; Williamson, 1985). The possibilities of opportunistic behavior are always present in an IT outsourcing situation (Gefen et al., 2008). Historical outcomes therefore guide that formal contracting by itself is not going to resolve the low success rate of IT outsourcing projects. Recent research has advocated that infusion of trust based governance to formal governance can help reduce the reliance on strictly contractual governance (Poppo \& Zenger, 2002).

Trust can foster norms of flexibility, solidarity, and information exchange (Gefen et al., 2008), in addition to covering lacunas of formal contracts (Poppo \& Zenger, 2002). Poppo and Zenger further proposed that among contractual exchanges, the kind that are neither integrated in-house nor managed through spot-market contracts, increases in exchange hazards shuld lead to more trust based governance. Thus, trust based governance can provide safeguards against hazards that may not be fully protected by formal contracts, thereby overcoming the limits of contracts (Goo et al., 2009). By encouraging interdependence, trust based governance (McEvily et al., 2003) provides the basis for such safeguards. Gefen (2004) found that a client's trust in an IT implementation situation was improved by process-based, characteristic-based, and institution-based trust generating mechanisms. Per Oza et al. (2005), trust in outsourcing means clients and vendors have positive expectations of each other's actions and at the same 
time possess rational interest in maintaining that relationship while being aware of the risks in those expectations. Thus, trust enables the two parties to negotiate uncertainties in their relationship in a nonconfrontational and cooperative manner. Trust can therefore be a particularly useful instrument to manage the outsourcing relationship between the client and the vendor given the geographical and social distance between the two parties in such relationships.

In the present study, process-based and institution-based mechanisms were theorized to lead to the process of generating user trust in a vendor.

\section{Process Based Trust Generating Mode}

In the process-based mode, trust is the outcome of the exchange process itself (Gefen, 2004; Zucker, 1986). The positive nature of the ongoing relationship helps generate trust (Ganesan, 1994; Gefen, 2004). Zucker (1986) states that process-based trust is tied to the exchanges, which could be past or even expected. In the case of an IT outsourcing project, it is hypothesized that users would evaluate their ongoing exchanges with the vendor to develop process-based trust. As an outcome of ongoing interactions with the vendor, users would evaluate their exchanges with the vendor and draw conclusions about their usefulness. Positive exchanges with the vendor would infuse users with the basis to form process-based trust.

\section{Institutional Based Trust Generating Mode}

Institutional trust is based on structures external to the trustor and the trustee such as membership of professional bodies or trust generating intermediary mechanisms. There are two types of institution-based modes for generating trust: The first mode consists of the guarantees emanating from the membership of a certifying body, and the second mode comprises the guarantees offered by an external actor promising proper execution of the transaction (Zucker, 1986). Institution-based trust indicates that one believes in the availability of required impersonal structures to enable one to act in anticipation of a successful future effort (Shapiro, 1987; Zucker, 1986). In a systems development project, the user's perception that the vendor is following processes prescribed by reputable body such as the Software Engineering Institute is likely to encourage the formation of trust through the institutional mode.

\section{CMMI and the Formation of Institutional Trust}

Researchers have previously assessed the impact of achieving high CMMI capabilities on project performance (Harkness, Kettinger, \& Segars, 1996; Herbsleb et al., 1997; Krishnan \& Kellner, 1999). Staples and Niazi (2008) conducted a systematic study to investigate the reasons behind organizational motivations for adopting CMMI-based SPI. Their findings identified improvement of product quality, improved project performance, customer satisfaction, and process-management improvements. Therefore, if the vendor has a high CMMI rating, that high CMMI rating of the vendor is likely to lend itself to formation of trust through the institutional trust generation mode between the user and the vendor. Institutional mechanisms often serve as certifiers and guarantees (Gefen, 2004). The high CMMI capability of the vendor is, in effect, an endorsement by a widely accepted and independent standards-setting and enforcement body such as SEI. This backing by the SEI is likely to provide users the confidence that the technical capability of the vendor will be of high quality. The standards-setting and enforcement body reduces the anxiety inherent in any IT outsourcing transaction by alleviating the technical risk to the project. One of the widely used generators of structural assurance in business transactions is the Better Business Bureau's seal of approval. Another example is the NIST, which creates a basis for institutional trust by providing independent third party assurances. CMMI acts as a comparable institutional trust-generating agency. IS research has not yet paid enough attention to CMMI acting as a source of institutional trust. Therefore, one of the hypotheses investigated by this study is that a vendor's high CMMI rating, acting as a guarantor of the vendor's technological capability, will lead to the formation of institutional trust between the user and the vendor

Even though the third type of trust generation mode proposed by Zucker (1986) is not included in the research model of this study, its discussion is provided below for completeness. According to Zucker (1986), the characteristic basis for trust is tied to people's attributes, ranging from family background to 
national origin. In this mode trust is built by generating shared expectations of what is happening and what is expected of all parties connected through a common background of customs and culture. Outsourcing projects usually involve people from geographically distant locations, who essentially interact only in an economic sense, therefore, personal similarity or common cultural background is not expected to play a major role in trust generation.

\section{FIGURE 2 \\ HYPOTHESIZED INTERACTION BETWEEN CMMI AND TRUST}

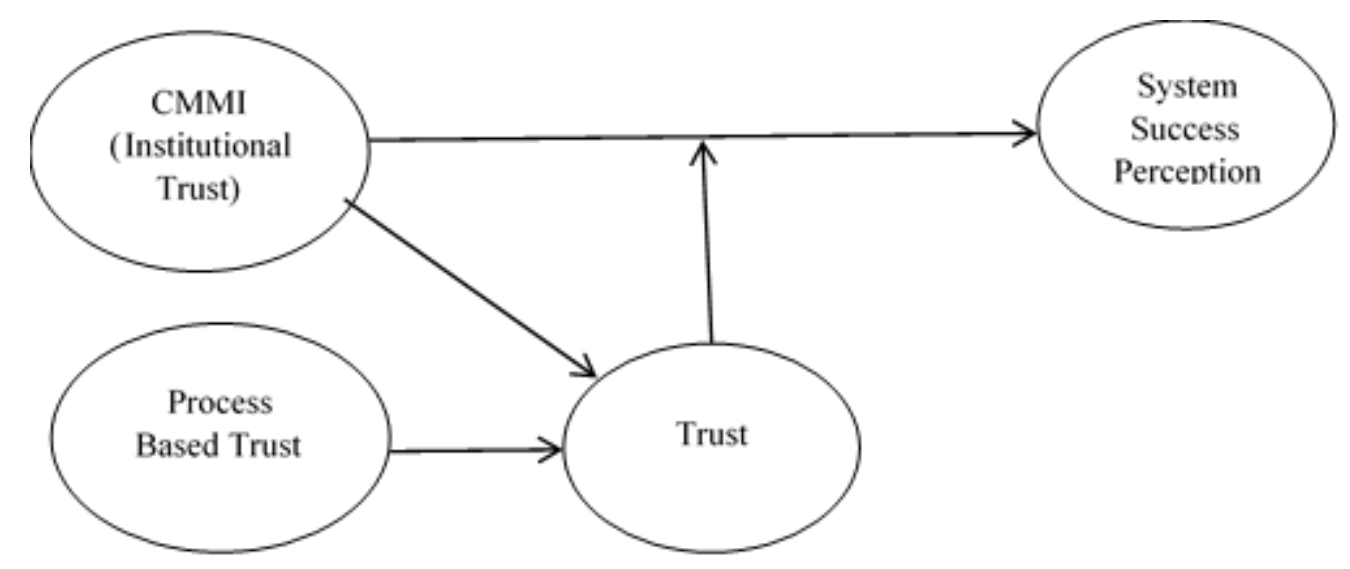

\section{INTERACTION BETWEEN TRUST AND CMMI}

CMMI is an indicator of the vendor's software development capability and trust based governance is likely to help achieve superior cooperation and coordination between the client and the vendor. IS research has not yet fully investigated whether presence of trust between the user and the vendor can impact the relationship between CMMI capability of the vendor and the user's system success perception, in terms of promoting or attenuating it. This study seeks to address this issue. In this study, the moderating role of trust on the relationship between CMMI and the user's system success perception is investigated. The two key characteristics of the hypothesized interaction are as follows:

1. At any given level of CMMI capability, the system-success perception of a user in a high-trust situation will be higher than the system-success perception of that user in a low-trust situation.

2. The impact of increase in vendor's CMMI capability will result in greater increase in systemsuccess perception in low-trust situation than in high-trust situation. 


\section{FIGURE 3 \\ RESEARCH MODEL}

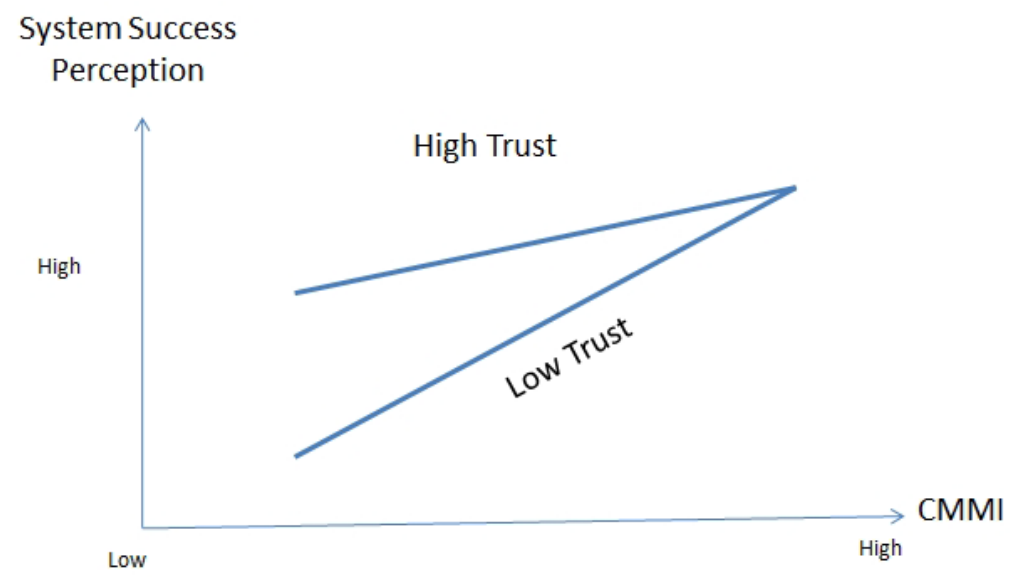

\section{HYPOTHESES INVESTIGATED BY THE STUDY}

The hypotheses investigated by this study are presented below.

\section{Institution Based Trust}

According to Zucker (1986), institutional trust extends beyond a given transaction or grouping of exchange partners. In situations of institutional trust, the construction of trust is intersubjective, external to any given situation, and part of the external world known commonly. Zucker (1986) further stated that institutional trust is of two types: (a) person or firm specific and (b) related to intermediary mechanisms. In situations of IT outsourcing, institutional trust can be formed between the user and the vendor if the vendor is a member of a renowned industry association, as that would be the signal of the vendor's connection to a reputable domain where expectations of trust are likely to hold true. Another instance could be the vendor having a high CMMI capability rating, as that would also convey to the user that the vendor possesses attributes usually associated with trustworthy entities. Institutional trust has been applied fairly extensively by studies investigating e-commerce transactions where interacting parties lack familiarity and cultural similarities (Pavlou, 2002; Pavlou \& Gefen, 2004). Such situations are in fact commonly found in IT outsourcing situations because transacting parties usually belong to widely different economic and social backgrounds. There is little likelihood of these parties working together on the basis of interpersonal trust. Just like online transactions involving parties who engage in exchange relationships despite a lack of any personal interaction, outsourcing often involves parties lacking adequate background information about each other. Dealings with a vendor that belongs to a distant geographical region, an alien culture, and an unfamiliar legal system are likely to be bolstered through the presence of institutional mechanisms of trust generation. Thus,

H1: User's perception of institutional trust will be positively related to trust between the user and the vendor.

\section{Process Based Trust}

A productive ongoing relationship can lead to perceptions of process-based trust (Zucker, 1986). According to Lindgreen (2003), process-based trust develops through a spiral of reinforcements resulting from interaction and can grow from fragile to robust. In an outsourcing-based software development project, the user is likely to accumulate, in his or her routine experiences, an assessment of the quality of the exchanges with the vendor. That assessment is likely to lay the foundation of the process-based trust 
between the user and the vendor. In the process-based mode, trust is created as a function of the exchange itself (Gefen, 2004; Zucker, 1986). Positive interactions such as transparency in dealings and regular and accurate feedback on project status are likely to reinforce the user's process-based trust. For the outsourcing firm, vendor opportunism and loss of control are the key components that threaten the project's success (Aubert et al., 1998; Aubert et al., 2004; Earl, 1996). Other threats to software development are based on the accuracy of cost estimation by the vendor, the availability of required capabilities, and the vendor's access to required technology and skills (Gefen et al., 2008). In process-based trust, a record of ongoing exchanges, often obtained secondhand or by imputation from outcomes of prior exchanges, provides data on the exchange process. Repeated exchanges with the vendor during an IT outsourcing project that appear to mitigate risks to the project are likely to promote the user's perception of process based trust. A healthy and professional ongoing relationship in which the vendor is perceived to be acting in a manner favorable to the project and above reproach is likely to foster process-based trust between the user and the vendor. According to Oshri et al. (2009), an outsourcing client is likely to take into account the extent to which an outsourcing provider was perceived to go the extra mile. A user's perception of the relationship as win-win because of vendor's actions is likely to generate trust in the vendor. Given that any given IT outsourcing project has many distinct sequential phases, such as contract negotiation, definition of requirements, and implementation, a positive reputation earned by the vendor in earlier phases of the project is likely to lead to process based trust between it and user as the project progresses. Thus,

H2: User's perception of process-based trust will be positively related to trust between the user and the vendor

\section{CMMI Capability of the Vendor and User's System Success Perception}

Software processes are improved by implementing work practices such as training, quality assurance, measurements, design and code reviews, and change control (Dekleva \& Drehmer, 1997). CMMI is one of the most popular quality-assurance processes for enhancing software quality and reducing development costs (Diaz \& Sligo, 1997; Harter et al., 2000). According to Diaz and Sligo (1997), each increase in CMMI level improves quality by a factor of 2 , usually reduces the cycle time, and improves productivity. According to Clark (2000), each level increase in CMMI capability reduces effort by 3 to 15 percent. Harter and Slaughter (2003) state that improvements in CMMI capability reduce the defect density of the software. Adopting software process maturity leads to improved product quality (Harter et al., 2000; Herbsleb et al., 1997). By graduating up through CMMI maturity levels, organization's software processes become more mature; that is, they become more disciplined and consistent as the organization adds practices such as design reviews, code reviews, configuration controls, and measurement (Krishnan \& Kellner, 1999). A vendor with high CMMI capability is therefore likely to be acknowledged as a result oriented and capable vendor. CMMI has been particularly effective at encouraging the outsourcing of IT software development (Kay, 2005). This has been possible because organizations have confidence in the ability of CMMI-based practices to ensure successful project development by external vendors in offshore locations.

According to Oshri et al. (2009), there are three key competencies of an outsourcing service provider that are important to the client. The first is delivery competency, which is based on the service provider's ability to respond to the client's ongoing needs, such as domain expertise and program-management and governance capabilities. The second competency is transformation competency, which is based on the service provider's ability to deliver radically improved service, both in terms of quality and cost. The third key competency is relationship competency, which is based on the service provider's willingness and ability to align its business model to the values, goals, and needs of the client. CMMI is designed to convey to the client that the vendor possesses these key competencies. Thus, CMMI is an established, standardized process-improvement methodology that inspires confidence in the minds of the users that a high CMMI level vendor is likely to produce a system that will meet the users' expectations and therefore ensures system success. Thus,

H3: The vendor's CMMI capability will be positively related to the user's system-success perception. 


\section{Trust Moderating Relationship Between Vendor CMMI Rating and User System Success Perception}

In this study it is hypothesized that in situation of high trust between the user and the vendor, the user's system-success perception will be higher at any given level of vendor CMMI capability than it would be in situation of low trust. However, an increase in the vendor's CMMI capability is not expected to have as great an increase in user's system-success perception in high-trust situation as in low-trust situation. This is because trust itself is likely to provide a strong impetus toward the formation of system-success perceptions, making CMMI capability relatively less important. Trust conveys the belief that the other party will stand by its commitments (Luhmann 1979; Rotter 1971). Luhmann (1979) further stated that the future consists of far more possibilities than can be realized by any individual, thus creating uncertainty. Trust helps reduce this complexity (Luhmann, 1979), thereby providing plausible, actionable possibilities. Trust can therefore enhance the tolerance of uncertainty. By lowering uncertainty and conveying the vendor's commitment to the project, trust is likely to be a positive influence on the user's system-success perception. In the presence of high trust between the user and the vendor, the third-party guarantee represented by the vendor's CMMI capability would certainly add to the existing system-success perception, which is already likely to be high, thereby strengthening it even further. However, the rate of increase in system perception is not likely to be as much as in low trust situation.

In situation of low trust between the user and the vendor, increase in vendor's CMMI capability is likely to have a greater positive impact on the user's system-success perception than in high-trust situation. This is because a vendor possessing a high CMMI capability level is more likely to ensure that the completed system will satisfy the client (Harter et al., 2000; Krishnan, Kellner, Kekre, Kriebel, \& Mukhopadhyay, 2000) and therefore will be accepted by the users. However, given that low user-vendor trust would have lowered the user's system-success perceptions to begin with, the overall system-success perception is not likely to be as high as it would be in situation of high trust. Lack of trust increases the cost of monitoring and enforcing contracts and heightens the possibility of opportunistic behavior (Bekmamedova et al., 2008). Even an outsourcing provider with a high CMMI capability needs to establish trust to strengthen the client's system success perceptions. Relationships based on formal contracts and rooted in mutual trust give rise to stronger bonds between clients and their service providers (Klepper, 1994; Lee, Huynh, \& Hirschheim, 2008; Sabherwal, 1999). Trust is considered to be a major component of the relationship quality between the client and outsourcing provider and to have a direct effect on the degree of outsourcing success (Lee et al., 2008). A low level or absence of trust, therefore, is likely to portend a relationship where each party relies on contractual obligations and threat of legal reprisal to enforce compliance with obligations. A lack of trust is also likely to lead to dissatisfying interactions and decreased faith in the relationship (Lee \& Kim, 1999), which in turn is likely to suppress the client's system-success perceptions even if the vendor is a high CMMI capability organization. Thus,

H4: Trust will moderate the relationship between the vendor's CMMI capability and the user's systemsuccess perception.

\section{SAMPLE, DATA COLLECTION AND ANALYSIS}

Data were collected through a questionnaire developed specifically for the present study. This study used a cross-sectional design to analyze data. An online survey was used to collect data from respondents. The items on the questionnaire were based on established instruments suitably modified for this study. The questionnaire was pretested for reliability and validity. The finalized questionnaire was then administered online to IT executives involved in IT outsourcing operations in their organizations. The contact information of such executives was obtained from multiple sources. The respondents were required to have either worked on an IT outsourcing survey in the past or be participating in an ongoing IT outsourcing project. The users' responses were analyzed through regression and interpreted for theoretical and practical implications. A total of 109 usable responses were collected out of over 350 total responses received. 
The majority of respondents in the survey were men $(83.2 \%)$ and the remaining (14.9\%) were women. Regarding IT experience, $73.3 \%$ of respondents had over 9 years' experience and the remaining respondents had fewer than 9 years' experience, with two missing cases. Regarding outsourcing experience, $31.7 \%$ had over 9 years' experience, $13.9 \%$ had 7 to 9 years' experience, $14.9 \%$ had 4 to 6 years' experience, $23.8 \%$ had 1 to 3 years' experience, and $13.9 \%$ had less than 1 year of experience. Regarding organization size, $37.6 \%$ worked in organizations with 1,000 or more employees, $12.9 \%$ worked in organizations with 500 to 999 employees, $17.8 \%$ worked in organizations with 100 to 499 employees, and the rest worked in organizations with fewer than 100 employees.

The data were collected separately for respondents currently engaged in IT outsourcing and respondents experienced but not currently engaged in outsourcing, therefore a MANOVA test was conducted to investigate whether the two separate groups could be combined in a single group for further analysis. For the MANOVA test, all variables from the two groups were entered, and no significant differences were found. As a result, the two groups were combined into one common data set. A demographic MANOVA was also conducted to examine whether the two groups were homogenous in terms of demographic attributes. The differences were not significant for age, race, gender, educational background, and total experience. A nonresponse test (MANOVA) was performed to compare the first 20 responses with the last 20 responses, and the differences were not significant.

For common method variance Hartman's single-factor test was performed. Only one single factor was extracted, without any rotation. The percentage of variance explained by this single factor was only $32 \%$, which is less than the commonly accepted cut off level of 50\%. Accordingly, common-method variance was not a major issue in this study. Multicollinearity tests were performed on the collected data and were found to be acceptable, meaning that no significant multicollinearity issues were found with the data. Cronbach's alpha for the entire data set was found to be 0.917 , revealing high reliability of the data set. A reliability analysis was performed on individual construct items as well and was found to be 0.745 and above.

An exploratory factor analysis was performed to determine how the items loaded on different factors. Any item that loaded at .40 on more than one factor or loaded on the wrong dimension was removed. The appropriate dimension selection was driven by judgment of where most items of that scale loaded. If any item of a scale loaded above 0.40 on a dimension that was not the dimension where most other items of that scale had loaded, that item was removed from the scale. The only exception to this rule was to include two items in the trust scale, capability, which loaded at .438 on another factor, and competence, which loaded at .437 on another factor. This was done so that the trust scale would not be reduced to a single-item scale and because there is strong theoretical support for these items being related to trust

Below the results of the analysis are discussed. 


\section{FIGURE 4 \\ INTERACTION EFFECTS}

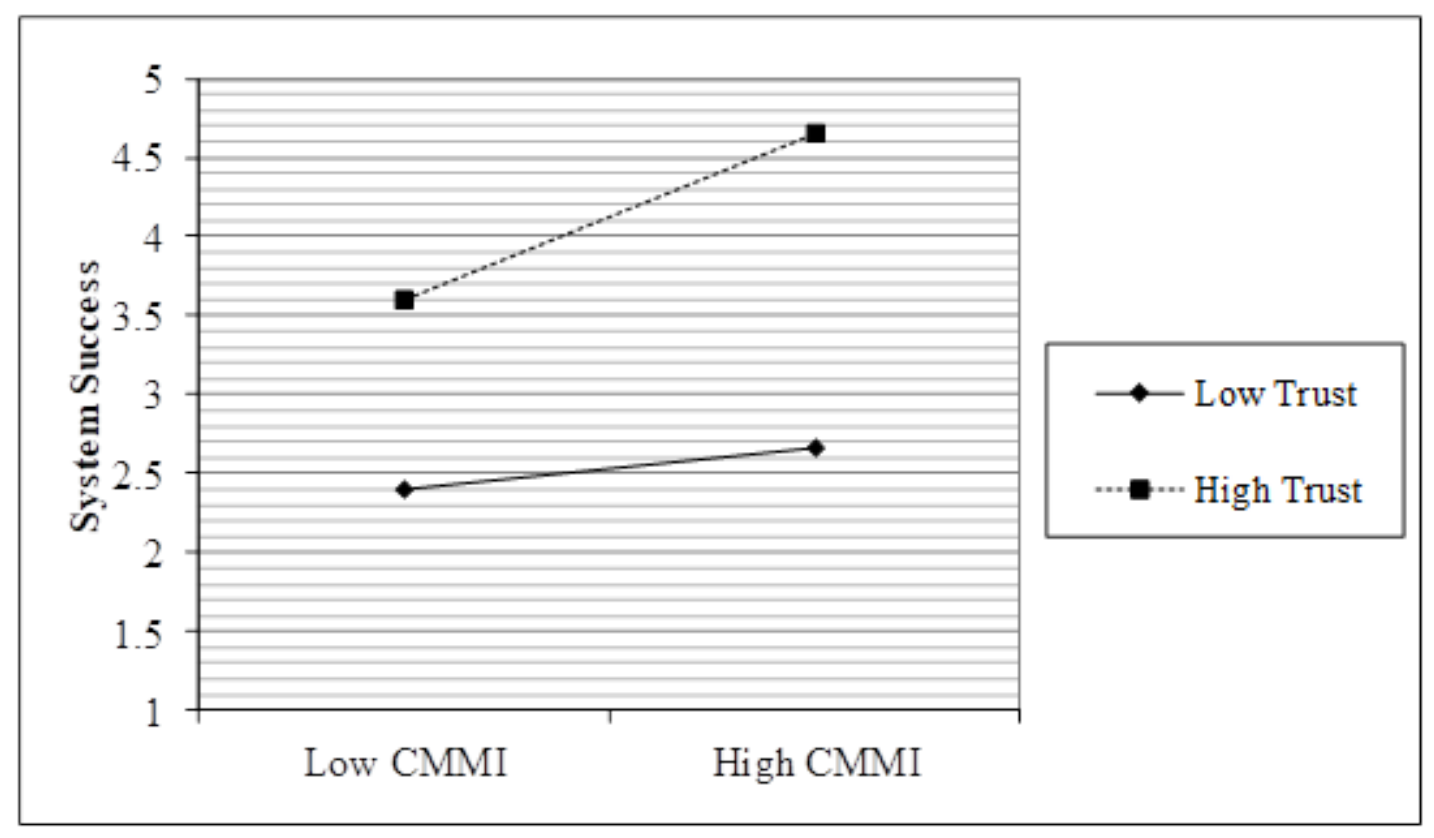

\section{RESULTS AND IMPLICATIONS}

\section{Hypothesis 1}

Hypothesis 1 stated that user's perception of institutional trust would be positively related to trust between the users and the vendor. This hypothesis was not supported. CMMI was used as the indicator of institutional trust in this study. According to Zucker (1986), institutional trust allows for a generalization of trust beyond a specific transaction or a specific set of actors. CMMI is a logical representation of institutional trust because it reflects the technical capability of the vendor in a generalized manner duly attested to by SEI.

\section{Implications}

The CMMI capability of the vendor, having been certified by an objective reputable third party, using transparent, published standards should likely generate institutional trust for the vendor. However, in this study the respondents did not associate the CMMI-rated capability of the vendor with institutional trust. A high CMMI rating provided evidence of technical prowess; however, it did not make the users trust the vendor. One of the reasons for this could be lack of widespread knowledge about the rigors of CMMI certification. It is not clear if users understood how vendors are able to obtain certification, what vendor qualities are authenticated by certification and the implications of certification to project outcomes. Unlike more well-known certification authorities such as the FDA or USDA, CMMI is not sponsored by the government and thereby perhaps lacks the weight of government approval. Accordingly, per the results of this study, CMMI capability was not perceived to be an unimpeachable assessment of vendor capability so as to generate institutional trust between the user and the vendor.

\section{Hypothesis 2}

Hypothesis 2 stated that process-based trust would lead to the formation of trust between the user and the vendor. This hypothesis was supported. 


\section{Implications}

The respondents to this study did agree with the hypothesis that positive interactions with the vendor are a basis for generating trust in the vendor. In IT outsourcing transactions, Oshri et al. (2009) referred to relationship competency as one of the key competencies to look for in a vendor. Oshri et al. described relationship competency as the vendor's willingness and ability to adjust its business model to the client's values, goals, and needs. Some of these competencies are related to planning and contracting, organizational design, governance, and program management. A vendor that creates accommodations for the client to meet the goals and needs of the client is likely to generate trust because the client will be able to rely on the vendor if the project runs into unexpected challenges and uncertainties. Process-based trust can arise from the accommodations that a vendor might make for the user.

\section{Hypothesis 3}

Hypothesis 3 stated that CMMI would be positively related to user's system-success perception. This hypothesis was not supported.

\section{Implications}

Maturity-level improvements in CMMI have been shown to lead to reduced error, shorter project duration, reduced costs through less rework, and less penalties due to time overruns. However, literature has also pointed to the fact that it is mostly large organizations that are adopting CMMI based software development practices given its demand for resources that many small companies cannot afford. A study by Brodman and Johnson (1994) found that small organizations, particularly those with 20 or fewer employees, do not have the resources to implement CMMI based software development practices. A further criticism of CMMI is positive selection bias, in that failed CMMI implementation efforts are simply ignored by researchers (Galin \& Avrahami, 2006). Another drawback with a CMMI-based approach has been the perceptions among many software developers that it is incompatible with agile development strategies such as Scrum. For instance, CMMI-based approaches are sometimes perceived to hamper a vendor' speed of software development and to have communication style more suited to a macro-organization with a wide scope, whereas in agile development the communication is more personal and takes place at the micro level (Turner \& Jain, 2002). It is possible that many respondents did not relate an organization that adopts a systematic, documented software development style afforded by CMMI to also be the one that will deliver a system that will be more likely to be adopted. Also, it is possible that many users might not have perceived vendor capability alone to be factor important enough to ensure system success. The results of this study point toward missing relationship between high CMMI capability and delivery of software that is likely to be adopted by the users in the minds of the users. Often reasons for system success reside within the client organization and not just with the developer. More research is needed to further investigate the perceived disjoint between high CMMI capability and system success.

\section{Hypothesis 4}

Hypothesis 4 stated that trust would moderate the relationship between CMMI and system-success perceptions. The interaction was significant, however, the increase in system success perception corresponding to increase in vendor CMMI capability in high trust situation was greater than increase in system success perception corresponding to increase in vendor CMMI capability in low trust situation, which is the opposite of what was hypothesized.

\section{Implications}

In high trust situation, the user assessed the vendor's high technical capability as further proof that the vendor would not only try to do a good job but might actually have the ability to deliver results as well. High vendor CMMI levels are associated with better development methods, lowered costs, and improved design methodologies (Galin \& Avrahami 2006). High CMMI capability tends to have a positive impact on the quality of the software and its development process (Gefen, Zviran \& Elman 2006). The high CMMI capability in turn reinforces belief in the vendor's ability and thereby further amplifies the impact of trust 
on system success perceptions. Win-win perception generated in the mind of the user through high trust and high vendor capability combined to create high system success perceptions (Oshri, Korlarsky and Willcocks 2009) as compared to low trust situation. Also, in high trust situation, increase in vendor CMMI capability added to the already high system success perception and thereby substantially enhanced system success perception greater than in low trust situation. Therefore in high trust situations, the CMMI capability and trust acted as complements to each other because of overlapping positive attributes.

In low trust situation, the system success perception was low to begin with and increase in CMMI capability was not enough to enhance system success perceptions above the level in high trust situation. Also, despite an increase in CMMI capability of the vendor, the system success perception increase was lower as compared to high trust situation. This result emphasizes the importance of trust in IT outsourcing projects. Trust is one of the ways people in a given environment overcome complexity and unpredictability (Gefen 2002) and IT outsourcing projects are prime examples of complex, unpredictable environment (Kern $\&$ Willcocks 2000). In such an environment, lack of trust can have a seriously undermining effect on the user's system success perception. One of the reasons increased CMMI capability was not able to overcome the effect of low trust could be that IT outsourcing projects are characterized by high levels of knowledge asset specificity (Goo \& Nam 2007). Low trust could signal to a user that the vendor might not actually develop project specific assets required for completing the project successfully. Such a perception of the vendor is likely to discourage belief in the vendor's ability to develop the system per user expectations. Another reason for failed IT outsourcing projects has been moral hazard. Companies can become vulnerable to the vendor if they outsource key features and services that differentiate their products because the vendor can sell those to their competitors (Ditmore 2012), thereby making trust a critical feature of relationship with the vendor. It can be concluded that just the ability of the vendor is not enough to produce high system success perception if the benevolence and integrity is missing on vendor's part.

TABLE 1

\section{SUMMARY OF RESULTS}

\begin{tabular}{ll}
\hline \multicolumn{1}{c}{ Hypothesis } & Result \\
\hline $\begin{array}{l}\text { 1. User's perception of institutional trust will be positively related to trust } \\
\text { between him/her and the vendor }\end{array}$ & Not supported \\
$\begin{array}{l}\text { 2. User's perceptions of process-based trust will be positively related to } \\
\text { trust between him/her and the vendor }\end{array}$ & Supported \\
3. Trust will moderate the relationship between CMMI capability of the & Supported \\
vendor and system-success perception of the user. & Not supported \\
4. CMMI capability of the vendor will be positively related to system- & \\
\hline
\end{tabular}

\section{CONTRIBUTION OF THE STUDY}

The results of this study confirm earlier studies that found process based trust to be positively related to trust. Trust was found to influence impact of vendor CMMI capability on user's system success perception. High trust, high CMMI situation was marked by higher system success perception as compared to situation with low trust. The presence of trust can provide a solid foundation for the functioning of the project, even if the main instrument of governance is contractual stipulations. Without trust, technical ability by itself will not be enough to improve the system success perception much. This study did not find CMMI capability of the vendor to be related to user's system success perception, which is surprising, however, further research can shed light on this finding. 


\section{REFERENCES}

Altinkemer, K., Chaturvedi, A., \& Gulati, R. (1994). Information systems outsourcing: Issues and evidence. International Journal of Information Management, 14(4), 252-278.

Aubert, B., Patry, M., \& Rivard, S. (1998). Assessing the risk of IT outsourcing. In R.H. Sprague, Jr. (Ed.), Proceedings of the Thirty First Annual Hawaii International Conference on System Sciences. Los Alamitos, CA.

Aubert, B., Rivard, S., \& Patry, M. (2004). A transaction cost model of IT outsourcing. Information and Management, 41(7), 921-932.

Bekmamedova, N., Prananto, A., McKay, J., \& Vorobiev, A. (2008). Towards better understanding of the relationship between formal controls and trust in IS outsourcing. ACIS 2008 Proceedings. Paper 53. Retrieved from http://aisel.aisnet.org/acis2008/53

Benaroch, M., Lichtenstein, Y., \& Robinson, K. (2006). Real options in IT risk management: An empirical validation of risk-option relationships. MIS Quarterly, 30(4), 827-864.

Clark, B.K. (2000). Quantifying the effects of process improvement on effort. IEEE Software, 17(6), 6570.

Dekleva, S., \& Drehmer, D. (1997). Measuring software engineering evolution: A Rasch calibration. Information Systems Research, 8(1), 95-104.

Diaz, M., \& Sligo, J. (1997). How software process improvement helped Motorola. IEEE Software, 14(5), $75-81$.

Dibbern, J., Winkler, J., \& Heinzl, A. (2008). Explaining variations in client extra costs between software projects to India. MIS Quarterly, 32(2), 333-366.

Ditmore, J. (2012). Why IT outsourcing often fails. Information Week. Retrieved from http://www.informationweek.com/it-leadership/why-it-outsourcing-often-fails/d/d-id/1105317?

Dutta, A., \& Roy, R. (2005). Offshore outsourcing: A dynamic causal model of counteracting forces. Journal of Management Information Systems, 22(2), 15-35.

Earl, M.J. (1996). The risks of outsourcing IT. Sloan Management Review, 37(2), 26-32.

Friedman, T.L. (2005). The world is flat. New York, NY: Farrar, Straus, \& Giroux.

Galin, D., \& Avrahami, M. (2006). Are CMM Program Investments Beneficial? Analyzing Past Studies. IEEE Software, 6(23), 81-87.

Gefen, D. (2002). Nurturing clients' trust to encourage engagement success during the customization of ERP systems. Omega, 30(4), 287-299.

Gefen, D. (2004). What makes an ERP implementation relationship worthwhile: Linking trust mechanisms and ERP usefulness. Journal of Management Information Systems, 21(1), 263-288.

Gefen, D., \& Carmel, E. (2008). Is the world really flat? A look at offshoring at an online programming marketplace. MIA Quarterly, 32(2), 367-384.

Gefen, D., Wyss, S., \& Lichtenstein, Y. (2008). Business familiarity as risk mitigation in software development outsourcing contracts. MIS Quarterly, 32(3), 531-551.

Gefen, D., Zviran, M., \& Elman, N. (2006). What can be learned from CMMI failures? Communications of AIS, 17(6), 2-28.

Goldenson, D.R., \& Gibson, D.L. (2003). Demonstrating the impact and benefits of CMMI: An update and preliminary results. Technical Report CMU/SEI-2003-SR-009, Software Engineering Institute.

Goo, J., \& Nam, K. (2007). Contract as a Source of Trust--Commitment in Successful IT Outsourcing Relationship: An Empirical Study. 40th Annual Hawaii International Conference on System Sciences. HICSS 2007, pp. 1-10

Goo, J., Kishore, R., Rao, H.R., \& Nam, K. (2009). The role of service level agreements in relational management of information technology outsourcing: An empirical study. MIS Quarterly, 33(1), $119-145$. 
Harkness, W.L., Kettinger, W.J., \& Segars, A.H. (1996). Sustaining process improvement and innovation in the information services function: Lessons learned at the Bose Corporation. MIA Quarterly, 20(3), 349-368.

Harter, D.E., \& Slaughter, S.A. (2003). Quality improvement and infrastructure activity costs in software development: A longitudinal analysis. Management Science, 49(6), 784-800.

Harter, D.E., Krishnan, M.S., \& Slaughter, S.A. (2000). Effects of process maturity on quality, cycle time, and effort in software product development. Management Science, 46, 451-466.

Herbsleb, J.D., Zubrow, D., Goldenson, D., Hayes, W., \& Paulk, M. (1997). Software quality and the capability maturity model. Communications of the ACM, 40(6), 30-40.

Hoyle, R.H., Harris, M.J., \& Judd, C.M. (2002). Research methods in social relations. Florence, KY: Wadsworth.

Huang, S.J., \& Han, W.M. (2006). Selection priority of process areas based on CMMI continuous representation. Information \& Management, 43(3), 297-307.

Isaac, G., Rajendran, C., \& Anantharman, R.N. (2004). Significance of quality certification: The case of the software industry in India. The Quality Management Journal, 11(1), 8-32.

Kay, R. (2005, January 24). CMMI. Computerworld. Retrieved from http://www.computerworld.com

Kern, T., \& Willcocks, L. (2000). Contracts, controls and presentation in IT outsourcing: Research in thirteen UK organizations. Journal of Global Information Management, 8(4), 15-29.

Klepper, R.J. (1994). Outsourcing relationships. In M. Khosrowpour (Ed.), Managing information technology investment with outsourcing (pp. 218-243). Harrisburg, PA: IDEA.

Klepper, R.J. (1995). The management of partnering development in IS outsourcing. Journal of Information Technology, 10(4), 249-258.

Krishnan, M.S., \& Kellner, M.I. (1999). Measuring process consistency: Implications reducing software defects. Management Science, 25(6), 800-815.

Krishnan, M.S., Kellner, M.I., Kekre, S., Kriebel, C.H., \& Mukhopadhyay, T. (2000). An empirical analysis of productivity and quality in software products. Management Science, 46(6), 745-759.

Lee, J.N., Huynh, M.Q., \& Hirschheim, R. (2008). An integrative model of trust on IT outsourcing: Examining a bilateral perspective. Information Systems Frontiers, 10(2), 145-163.

Lindgreen, A. (2003). Trust as a valuable strategic variable in food industry. British Food Journal, 105(6), 310-327.

Loh, L., \& Venkataraman, N. (1992). Determinants of information technology outsourcing: A crosssectional analysis. Journal of Management Information Systems, 9(1), 7-24.

Luhmann, N. (1979). Trust and power. Chichester, England: Wiley.

Maxwell, K., Wassenhove, L.V., \& Dutta, S. (1999). Performance Evaluation of General and Company Specific Models in Software Development Effort Estimation. Management Science, 45(6), 787 803.

McDougall, P. (2006). Dexterity required. InformationWeek, 19, 34-39.

McEvily, B., Perrone, V., \& Zaheer, A. (2003). Trust as an organizing principle. Organization Science, 14(1), 91-103.

Ngwenyama, O., \& Nielsen, P.A. (2003). Competing values in software process improvement: An assumption analysis of CMM from an organizational culture perspective. IEEE Transactions on Engineering Management, 50(1), 100-112.

Oshri, I., Kotlarsky, J., \& Willcocks, L.P. (2009). The handbook of global outsourcing and offshoring. New York, NY: Palgrave MacMillan.

Oza, N., Hall, T., Rainer, A., \& Grey, S. (2005). Trust in software outsourcing relationships: An empirical investigation of Indian software companies. In 9th International Conference on Empirical Assessment in Software Engineering. Keele, UK.

Parzinger, M.J., \& Nath, R. (2000). A study of the relationships between total quality management implementation factors and software quality. Total Quality Management, 11(3), 353-371.

Paulk, M., Weber, C.V., Curtis, B., \& Chrissis, M.B. (1998). The capability maturity model: Guidelines for improving the software process. Reading. MA: Addison Wesley. 
Paulk, M., Weber, C.V., Garcia, S.M., Chrissis, M.B., \& Bush, M. (1993). Key practices of the capability maturity model (Version 1.1). CMU/SEI-93-TR-025. Pittsburgh, PA: Carnegie Mellon.

Pavlou, P.A. (2002). What drives electronic commerce? A theory of planned behavior perspective. Proceedings of the Academy of Management Conference. Denver, CO.

Pavlou, P.A., \& Gefen, D. (2004). Building effective online marketplaces with institution based trust. Information Systems Research, 15(1), 37-59.

Poppo L., \& Zenger, T.R. (2002). Do formal contracts and relational governance function as substitutes or complements? Strategic Management Journal, 23(8), 707-725.

Rotter, J.B. (1971). Generalized expectancies for interpersonal trust. American Psychologist, 26, 443450.

Royce, W. (2002, February). CMM vs. CMMI: From conventional to modern software management. The Rational Edge. Retrieved from http://www.cdainfo.com/down/1-Desarrollo/CMM2.pdf

Sabherwal, R. (1999). The role of trust in outsourced IS development projects. Communications of the $A C M, 42(2), 80-86$.

Shapiro, S.P. (1987). The social control of impersonal trust. American Journal of Sociology, 93(3), 623658.

Smith, A. (1776). The wealth of nations. New York, NY: Random House.

Software Engineering Institute (SEI). (2008). What is CMMI? Retrieved from https://www.sei.cmu.edu/cmmi/

Staples, M., \& Niazi, M. (2008). Systematic review of organizational motivations for adopting CMM based SPI. Information and Software Technology, 50(7-8), 605-620.

Statista. (2015). Worldwide spending for IT outsourcing (ITO) services from 2011 to 2013 (in billion U.S. dollars). Retrieved from http://www.statista.com/statistics/298554/global-spending-itoutsourcing-market

Subramanian, G.H., Jiang, J.J., \& Klein, G. (2007). Software quality and IS performance improvements from software development process maturity and IS implementation strategies. The Journal of Systems and Software, 80(4), 616-627.

Turner, R., \& Jain, A. (2002) Agile Meets CMMI: Culture Clash or Common Cause? Second XP Universe and First Agile Universe Conference Chicago, IL, USA, August 4-7, 2002 Proceedings, pp. 153-165.

Zucker, L.G. (1986). Production of trust: Institutional sources of economic structure, 1840-1920. In B. M. Staw \& L.L. Cummings (Eds.), Research in organizational behavior. Greenwich, CT: JAI Press. 